\title{
Pervasive Fibre-Optic Sensor Networks in Bridges: A U.K. Case Study
}

\author{
L.J. Butler ${ }^{1,2}$, M.Z.E.B. Elshafie ${ }^{1,3}$ and C.R. Middleton ${ }^{1}$ \\ ${ }^{1}$ Department of Engineering, University of Cambridge, Cambridge, United Kingdom \\ ${ }^{2}$ Lloyd's Register Foundation Programme on Data-Centric Engineering, The Alan Turing Institute \\ ${ }^{3}$ Visitor at the Department of Civil and Architectural Engineering, Qatar University, Qatar
}

\begin{abstract}
Integrating fibre-optic sensor networks in a newly-constructed infrastructure assets enables datadriven performance assessment during its construction and throughout its operational life. As part of a multimillion pound railway infrastructure redevelopment project, two new railway bridges were instrumented with an extensive network of both discrete (fibre Bragg gratings or FBGs) and distributed (based on Brillouin optical time domain reflectometry or BOTDR) fibre optic sensors to measure both strain and temperature throughout construction and in-service. Completed in 2016 in Staffordshire UK, both 'self-sensing' bridges contain more than 500 fibre Bragg grating sensors and over 600 metres of distributed fibre optic sensor cabling. This paper describes the sensing technologies employed, installation techniques for improving sensing robustness, the monitoring programme and objectives, data processing methods and assumptions, and the primary monitoring findings of this project. Results related to measurements of prestress losses in prestressed concrete girders, estimates of steel girder deflection using FBGs and videogrammetry, and assessments of percentage utilisation of critical superstructure elements are presented. In terms of future directions, BIM-based environments which incorporate sensor elements and an emerging field of research known as Data-Centric Engineering are introduced as tools to better manage, maintain and learn from the information generated from self-sensing infrastructure.
\end{abstract}

\section{INTRODUCTION AND BACKGROUND}

Smart infrastructure results from the combination of physical (i.e. bridges, tunnels, roads, etc.) and digital (i.e. sensors, internet of things, GIM, etc.) infrastructure, leading to more reliable information to enable better, cheaper and faster decision making (CSIC 2016).

From a U.K. perspective, there are a number of challenges facing the infrastructure management sector. In particular, these challenges include, pressures to maintain adequate levels of asset performance under shrinking financial budgets; aging assets which require ever-increasing maintenance and upgrading; tighter government regulations requiring greater accountability and risk assessment; and the unknown future effects of climate change (ICE 2017). To combat these challenges, smarter infrastructure is required. It has been estimated that the smart infrastructure sector has the potential to create opportunities worth anywhere between $£ 2.4$ and $£ 4.8$ trillion (\$3.2 and \$6.3 trillion) globally (CSIC 2016).

Within the envelope of smart infrastructure systems is the concept of 'self-sensing' (or 'sensory') structures. These structures use measurements from embedded sensing systems to provide information on their internal state (Measures 1992). Any structure can be converted into a 'self-sensing' structure whether the sensor system is installed during construction or long after the structure has been in operation. Bridges are good candidates for implementing a sensing system as they represent critical assets within road and rail networks and their long-term in-situ performance, particularly how they deteriorate, has not been well categorized. Therefore, sensing systems, at a minimum, should be designed to function reliably in the long-term. Most importantly, sensor and monitoring systems in general should not be implemented before defining the purpose of monitoring for a particular asset or application. Further guidance on structural health monitoring (SHM) system selection for bridges is provided in Vardenega et al. (2016), Webb et al. (2015) and Middleton et al. (2016).

First appearing in the early 1990s, fibre optic based sensor systems have been installed to monitor a variety of bridge types around the world. In Australia, fibre optic sensors (fibre Bragg gratings) installed externally in combination with digital image correlation techniques were used to measure strain during load testing of a prestressed concrete girder bridge (Gowripalan et al. 2016). Similar bridge 
monitoring studies which incorporate the use of fibre optic sensing have been undertaken in Canada (Tennyson et al. 2001; Regier and Hoult 2014), the United States (Cardini and DeWolf 2009; Glisic 2012), Sweden (Jemli et al. 2003), Portugal (Costa and Figueiras 2012), China (Chan et al. 2006) and India (Scott et al. 2013). Compared with electricalbased sensors, FOS have several advantages including being corrosion resistant, having higher accuracy, good long-term stability and requiring less cabling (and therefore reduced interrogator channel requirements).

In the U.K., while traditional SHM systems have been deployed across various large-scale bridge projects, the use of fibre optic sensing has been very limited (Webb et al. 2017; Lydon et al. 2017). This paper presents a new fibre-optic-based bridge sensing case study. Completed in April 2016, the Stafford Area Improvements Programme (SAIP) involved a major upgrade and redevelopment on the West Coast Main Line near Crewe including the construction of 11 new bridges.

An Innovate UK and EPSRC-funded research project in collaboration with the Staffordshire Alliance (Network Rail, Laing O'Rourke, Atkins, and VolkerRail) and the University of Cambridge's Centre for Smart Infrastructure and Construction (CSIC) constructed, to the authors' current knowledge, the most densely-instrumented 'selfsensing' railway bridges in the U.K. Two of the 11 new bridges (one steel composite and one prestressed concrete) constructed as part of the SAIP were extensively instrumented as prototypes containing durable, permanent, fibre-optic based strain monitoring systems.

This paper provides an overview of the monitoring system and sensing technologies, innovative techniques for improving sensing system robustness, data processing and analysis assumptions, and the primary monitoring findings. Additional insight is provided into new tools related to self-sensing infrastructure and the emerging research area known as data-centric engineering.

\section{SELF-SENSING BRIDGE PROTOTYPES}

\subsection{Description of bridge structural systems}

Intersection Bridge 5 is a steel half-through skewed $\left(22.6^{\circ}\right)$ railway bridge formed by two 2.2 metre deep main I-girders with composite concrete deck supported on transverse steel cross beams. It carries two new lines of ballasted track and forms the primary structure in the SAIP as it crosses the existing West Coast Main railway line. It has a single skew span of 26.8 metres and is simply-supported on piled abutments. To provide lateral buckling restraint of the top I-girder flanges, U-frames consisting of vertical stiffeners at corresponding moment-connected steel cross beam locations are provided at every three metres. This bridge type was selected for this application to achieve construction depth requirements.

Underbridge 11 is a prestressed concrete girder bridge with infill concrete deck simply-supported on elastomeric bearings on piled abutments. The 11.2 metre span carries one line of ballasted track over a minor watercourse. Seven prestressed concrete (PC) TY7 internal beams and two PC TYE7 edge beams form the main superstructure. The 0.7 metre deep PC beams were precast offsite 6 months prior to being erected on the abutments. A $200 \mathrm{~mm}$ thick reinforced concrete deck slab and solid concrete infill in between the PC beams were cast in-situ. Transverse tie bars were installed across the deck through web opening holes in the PC beams. An additional concrete slab bridge was constructed adjacent to Underbridge 11 which forms part of a pedestrian footpath. This bridge type was selected for this particular application because it promoted offsite manufacture and led to reduced erection times and construction costs. Figure 1 depicts the completed self-sensing bridges.

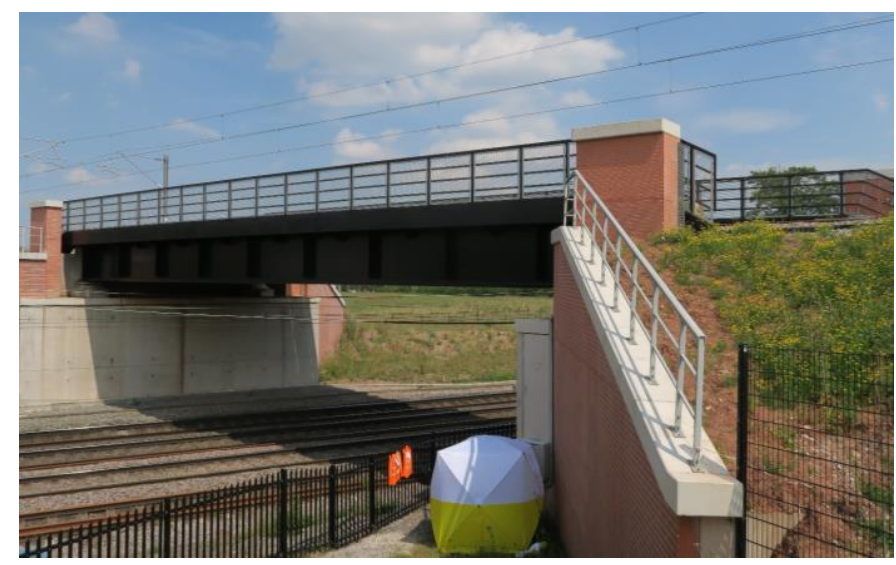

(a) Intersection Bridge 5

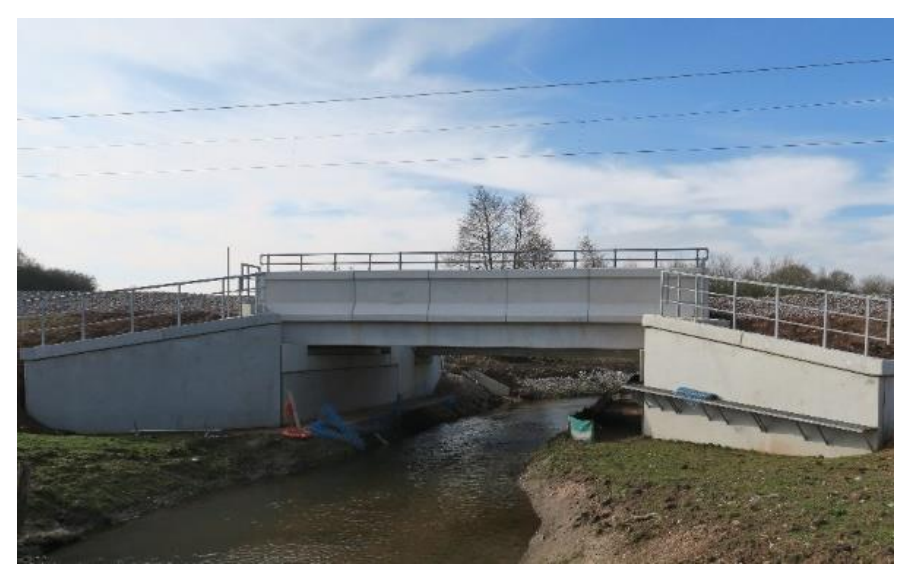

(b) Underbridge 11

Figure 1. Completed self-sensing railway bridge prototypes

\subsection{Sensing system technology}

Fibre optic sensors (FOS) are typically grouped within two main categories: discrete and distributed. 
This research study involved the combined use of both types of FOS, discrete FOS known as fibre Bragg gratings and distributed FOS based on optical time domain reflectometry (OTDR).

Bragg gratings are written into the core of an optical fibre typically using an excimer laser. The refractive index at the grating locations are altered compared with the adjacent fibre. This creates a dielectric mirror which reflects laser (ultraviolet) light at a specific frequency. Typically, several (up to 20 or greater) FBGs can be written each with different Bragg wavelengths along a single fibre. When an FBG is stretched, the grating period shifts which results in a change in wavelength of the reflected ultraviolet light (Kreuzer 2006). This change in wavelength is then converted to an equivalent change in strain. The FBGs used as part of this study were formed using a draw tower process and were coated with glass fibre reinforced polymer coating for added robustness during installation. Sensor arrays with up to 20 FBGs at one metre spacing were produced. Using an optical fibre interrogator combined with an optical fibre multiplexer, both produced by Micron Optics, it was possible to record strain changes at 250 $\mathrm{Hz}$ of up to 320 individual FBG sensors simultaneously.

Distributed FOS sensors, on the other hand, have the ability to measure strain changes along the entire length of a fibre optic cable. Based on the optical time domain reflectometry (OTDR) technique, an optical pulse (laser light) is shone down an optical fibre where a photodetector measures the amount of backscattered light in the fibre. Knowing the speed of light, the time information is converted to distance. One particular backscattered light component known as Brillouin scattering, carries information about the temperature and amount of strain in the fibre based on its wavelength shift; this is known as Brillouin Optical Time Domain Reflectometry (BOTDR) (Glišić and Inaudi 2007). The BOTDR cable used as part of this study was a steel-reinforced single-mode low bend loss fibre. Strain values are averaged over a $50 \mathrm{~cm}$ length are taken at steps of $5 \mathrm{~cm}$ along the entire cable. Unlike FBG sensors, BOTDR based sensing is not suitable for capturing dynamic strain changes as measurement times of 5 minutes or greater are typical depending on the length of cable.

FOS are particularly sensitive to temperature changes (i.e. index of refraction is altered and the glass fibre expands or contracts) and therefore, various compensation techniques are required in order to isolate temperature effects and obtain mechanical strains. Separate temperaturecompensation FO sensors for both the FBG and BOTDR FOS were implemented on this project to account for these effects.

\subsection{Sensor topologies and installation}

On Underbridge 11, a combination of FBG and BOTDR sensors were employed. Figure 2 depicts an overview of the sensor topology for Underbridge 11. A primary objective of the monitoring programme was to assess and compare the strain measurements provided by both systems.

In total, six of the nine prestressed concrete (PC) beams were instrumented along the top and bottom prestressing strands with 10 strain FBGs, 6 temperature FBGs and both strain and temperature BOTDR sensing cables. All PC beam instrumentation was completed at the pre-casting facility following prestressing of the strands before pouring of the concrete. The early-age behaviour of the beams was then assessed prior to their erection on the bridge abutments (refer to Butler et al. 2016 for further details). Additional sensors were then installed along the top layer of reinforcing in the concrete deck (6 FBGs) and along the transverse ties (4 FBGs) at both midspan and quarterspan locations (refer to Figure 2). Sensors were secured to the prestressing strands and reinforcing steel using plastic ties spaced at approximately $300 \mathrm{~mm}$.

Only FBG sensors were installed on Intersection Bridge 5 as depicted in Figure 3. The main west and east girders were instrumented with 20 strain and temperature compensating FBGs along both the top and bottom flanges. Two cross beams, one at midspan and one near the end (skew) span were also instrumented with 7 strain and temperature FBGs along the top and bottom flanges. At the instrumented cross beam locations, 7 strain and temperature FBGs were installed within the transverse concrete deck along the top layer of reinforcing steel. One of the web stiffeners forming part of the midspan U-frame was also instrumented with 6 vertically oriented FBGs (4 strain and 2 temperature). Following cleaning and abrasion of the surface of the steel superstructure, the FBG sensors were attached using a structural adhesive. The final surface painting system was then applied by the bridge contractor following sensor installation. FBGs installed within the concrete deck were attached to the reinforcing steel using plastic cable ties spaced at approximately $300 \mathrm{~mm}$.

The most vulnerable component of the installed fibre optic sensor networks are the splices between both the primary sensor array and the routing cables and optical connectors. For this reason, a series of special splice protector designs were devised in the laboratory prior to sensor deployment. Combined with the ruggedized coatings applied to the sensor cabling, the final installed sensor network has so far 


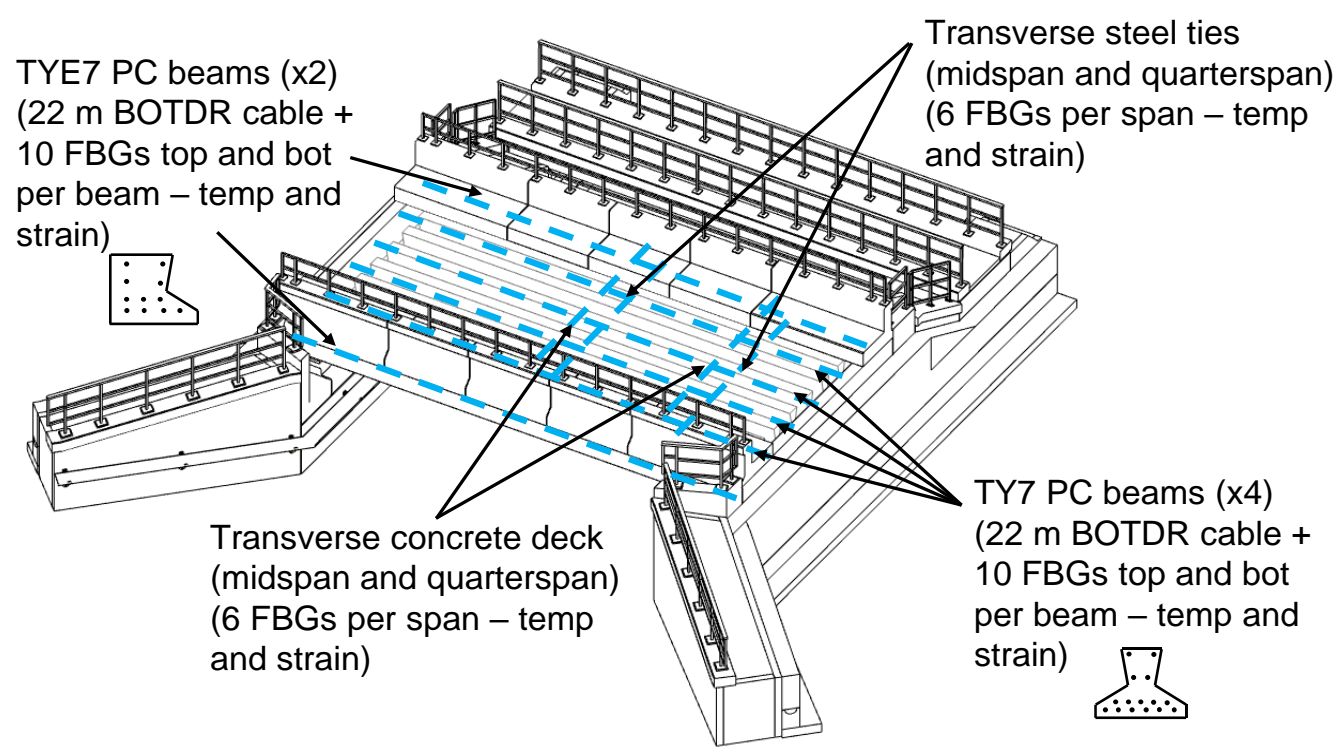

Figure 2. Sensor topology for Underbridge 11

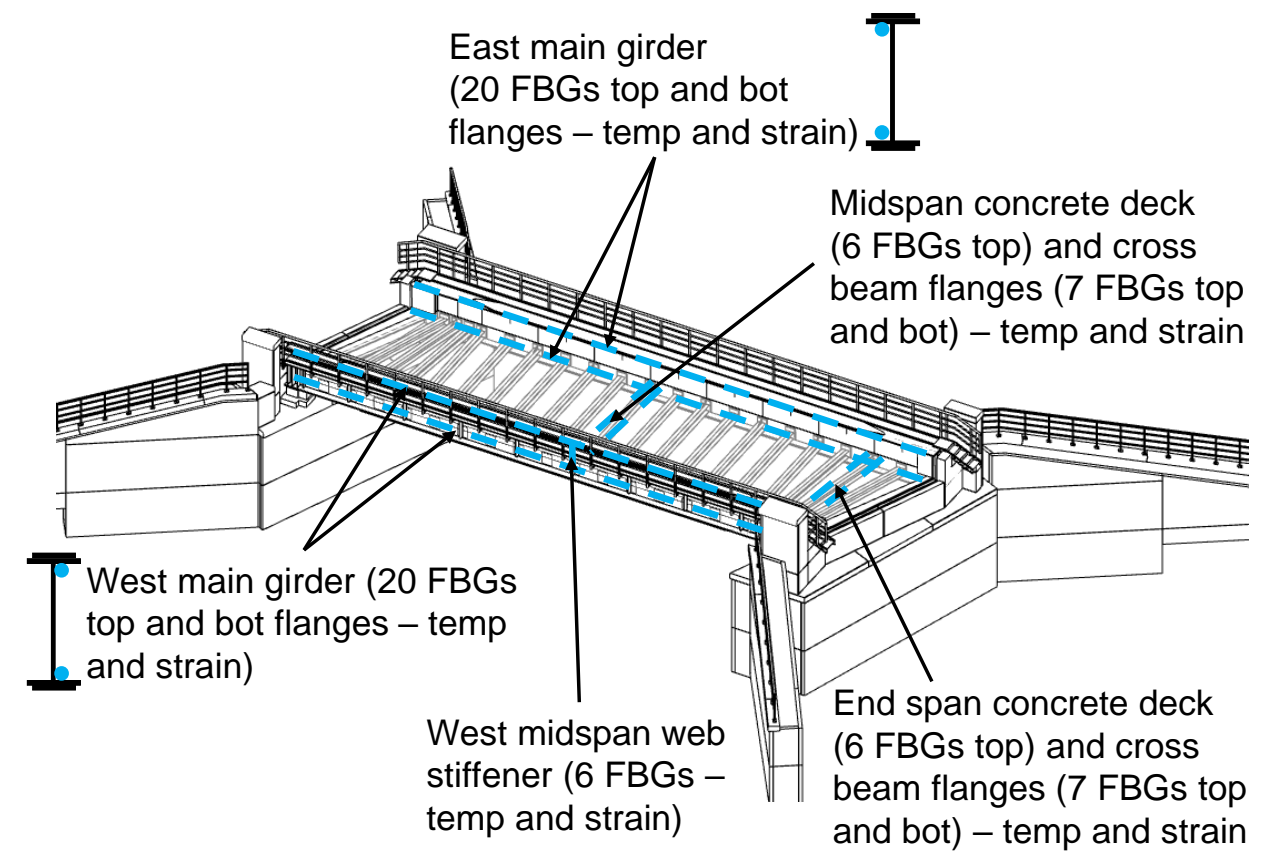

Figure 3. Sensor topology for Intersection Bridge 5

proven to be highly resilient during its first two years in operation.

\section{MONITORING RESULTS AND DISCUSSION}

The installation of the monitoring systems for both bridges was completed by the fall of 2015 and both bridges were opened to rail traffic by March 2016. Since their opening, two additional monitoring visits occurred in July 2016 and one year later in July 2017. The following section presents an overview and discussion of some of the key findings to date.

\subsection{Prestress losses in PC beams (Underbridge 11)}

A primary focus of monitoring Underbridge 11 was to assess the early age and long-term prestress losses within the PC beams. In particular, the strain changes measured from the FBG sensors were used to estimate the change in prestress during the first two years of the internal TY7 (average of two) and external TYE7 (average of two) PC beams as presented in Figure 4.

Changes in prestress were calculated based on the interpolated strains acting through the centroid of the prestressing steel. Note that baseline stress values were taken from a time immediately prior to detensioning of the prestressing strands. The total measured change in prestress for the TY7 and TYE7 PC beams between January 2015 and July 2017 were $211 \mathrm{MPa}$ and $165 \mathrm{MPa}$, respectively. The values of long-term prestress losses calculated using Eurocode 2 (according to EN 1992-2, BSI 2004) are presented in Butler et al. (2016). The total (120 year) estimated 
prestress losses for the TY7 and TYE7 PC beams were $275 \mathrm{MPa}$ and $267 \mathrm{MPa}$, respectively. Therefore, the measured prestress changes for the TY7 and TYE7 PC beams were $77 \%$ and $62 \%$ of the Eurocode 2 estimated ultimate losses, respectively. Based on the estimated change in prestress from the FBG strain measurements, it appears that the loss of prestress in the TYE7 beams (average of two beams) is greater than the loss in the TY7 beams (average of two beams).

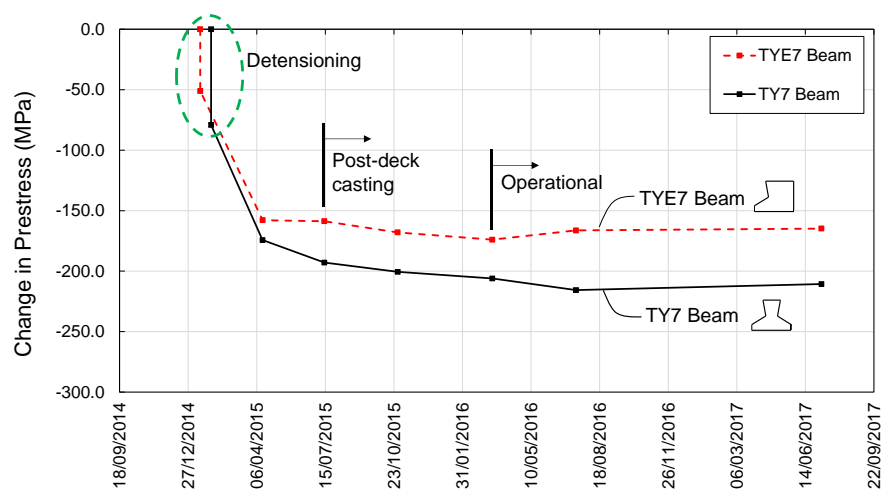

Figure 4. Estimated change in prestress in PC beams from FBG strain measurements

This difference in prestress losses appears to stem from greater elastic shortening losses during the detensioning process. Based on Figure 4 it appears that the value of the prestress losses increase slightly after the bridges become operational. It is suspected that ambient effects (i.e. temperature, relative humidity, wind, etc.) may account for these anomalies however, further research is required to better understand this effect.

In comparing discrete versus distributed fibre optic sensor technology, a previous study by the authors reported that the FBG and BOTDR measured strains during the first six months following beam casting were similar (Butler et al. 2016).

\subsection{Steel girder deflections under live loading (Intersection Bridge 5)}

Strain measurements taken from the FBG sensors $\left(\varepsilon_{\mathrm{FBG}}\right)$ installed along the top and bottom flanges of the two main girders were used to estimate the midspan deflections under passing trains. Based on the assumption of Euler-Bernoulli beam bending and using linear regression to fit a set of polynomial basis functions $\left(a_{i} \varphi_{i}\right)$ to the curvature calculated from the strain data, double integration was performed numerically to obtain estimates of the girder's vertical deflection at a given time $\mathrm{t}_{\mathrm{i}}, \mathrm{w}\left(\mathrm{x}, \mathrm{t}_{\mathrm{i}}\right)$, along the total length $\mathrm{L}$, of the girder. The midspan deflection $\left(W_{\text {midspan }}\left(t_{\mathrm{i}}\right)\right)$ at a given time $\mathrm{t}_{\mathrm{i}}$, is then reported as $\mathrm{W}\left(\mathrm{L} / 2, \mathrm{t}_{\mathrm{i}}\right)$. This procedure is repeated for each time step (in this instance at 250 times per second which is equivalent to the FBG sensor acquisition rate) and for each FBG top and bottom pair (20 in total per girder). A summary of the algorithm was implemented using Matlab and is outlined below:

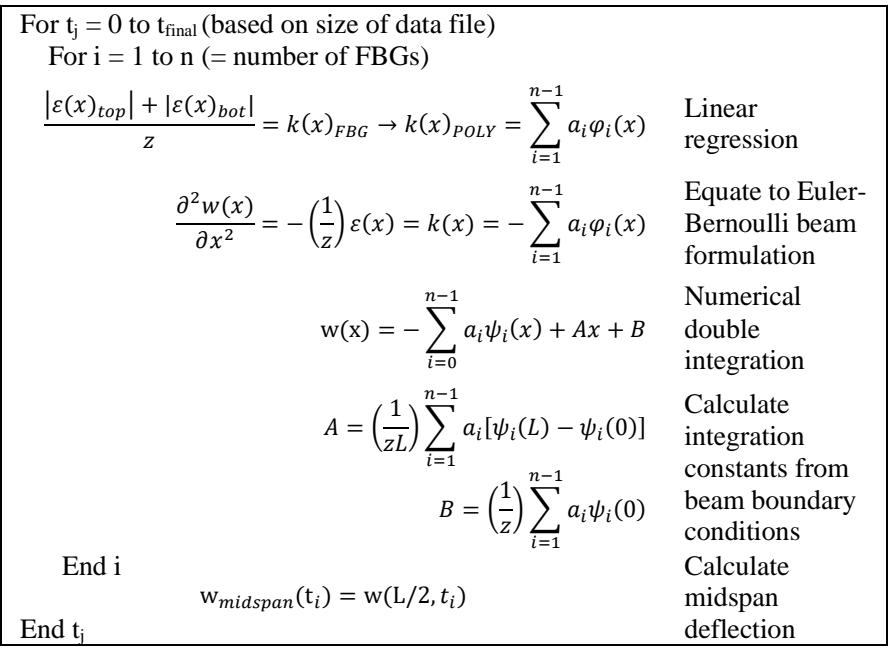

This methodology is similar to methods reported by Vurpillot et al. (1996) and Todd et al. (2000). It was assumed that the girder was simply-supported implying a vertical deflection of zero at both ends. A third-order polynomial was chosen as a basis function and was found to provide an adequate fit to the calculated curvature data. To validate the FBGcalculated deflection results, an advanced videogrammetry system produced by Imetrum was used to measure the midspan deflection of the east main girder when a 4-car passenger train passed over the bridge (refer to Figure 5 and Figure 6).

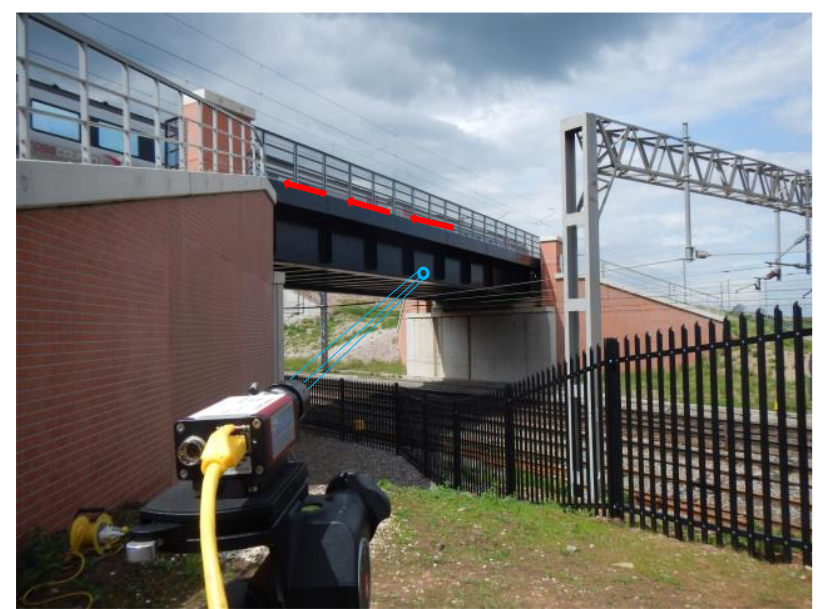

Figure 5. Videogrammetry system setup for measuring midspan deflection of east main girder

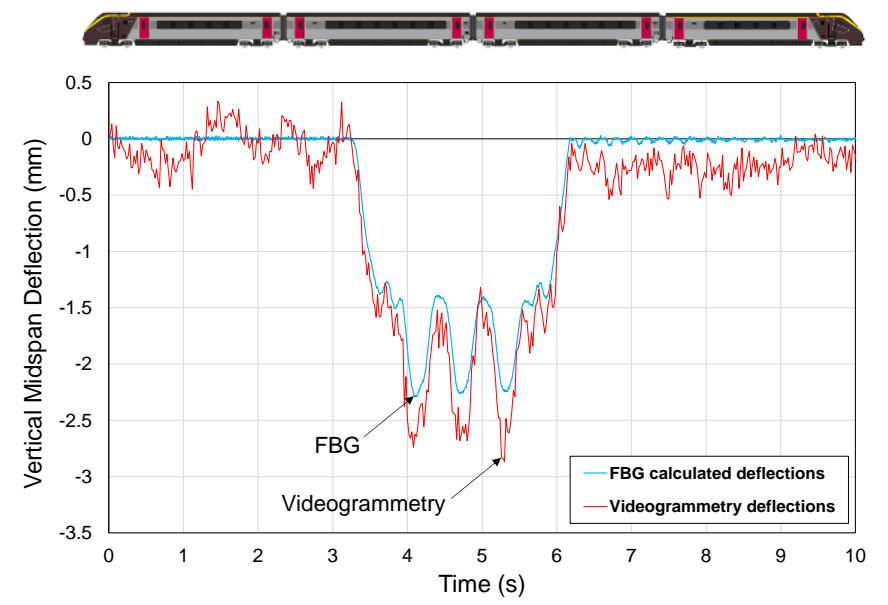

Figure 6. Midspan deflection of east main girder versus time using $F B G$ back-estimated and videogrammetry measurements 
The FBG-estimated midspan deflection results followed a very similar deflection profile as compared to the videogrammetry based results. On average, the maximum (corresponding to the peak deflection values in Figure 6) midspan deflections measured using the videogrammetry system were $18 \%$ higher than those estimated from the FBG strain measurements. This difference may be due to inherent errors in measurement of the videogrammetry system and also due to errors which arise within the back-calculation of deflection via double integration of the FBG-strain measurements. While additional monitoring data from both the FBGs and videogrammetry are required, the initial results of these two deflection estimation methods seem promising.

\subsection{Percentage utilisation assessment}

A primary benefit of integrating sensing within a structure is the ability to estimate and assess levels of performance in-service. In particular, the FBG sensors installed within Intersection Bridge 5 along the top and bottom flanges of the main girder can be used to estimate the curvature and moment demand under average daily rail loading. Calculated moment demand envelopes can then be generated and updated as more data is collected. As an example, Figure 7 presents the moment demand envelopes for both main girders based on FBG strain data collected from 12 trains passing over the bridge over a period of 8 hours. During this period, only two passenger train types, Class 350 'Desiro' and a Class 221 'Super Voyager' passed over the bridge. Note that the measurement results seem to indicate a sensor malfunction on the east main girder possibly due to localized debonding.

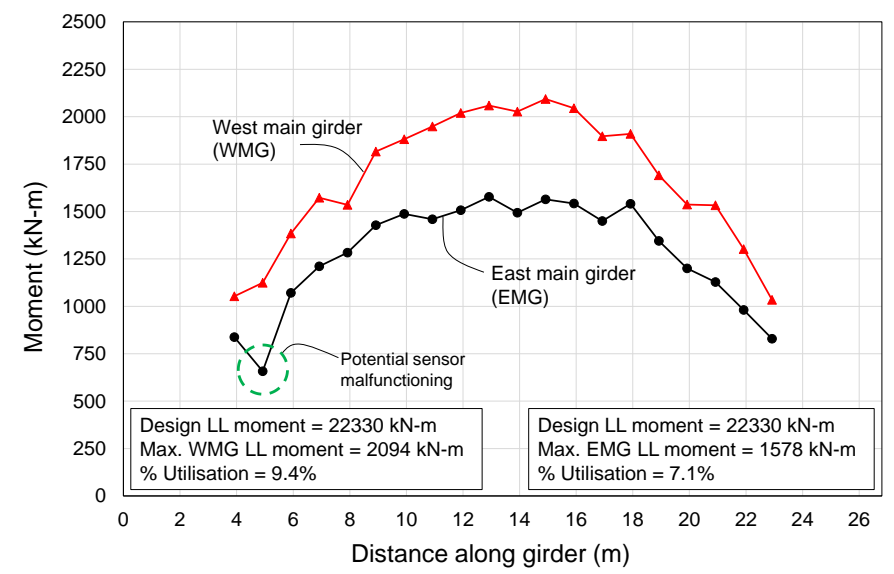

Figure 7. FBG estimated moment demand envelopes for the main girders on Intersection Bridge 5

To provide an estimate of the percentage utilisation of each girder considering the data collected from the 12 trains, the (ultimate) design live load moment capacity of the girder section must be calculated. Using Eurocode design equations (BSI 2005, 2006 ) for calculating the capacity of the main I-girders and based on previous studies by the authors (Delgado et al. 2017) the design moment capacity under live loading (M $\mathrm{M}_{\mathrm{DES}, \mathrm{LL}}$ ) is $22.3 \mathrm{MN}-\mathrm{m}$. Therefore, based on the sensor data-generated moment envelopes, the west main girder and east main girder have percentage utilizations of $9.4 \%$ and $7.1 \%$, respectively. Note that the west main girder appears to be consistently supporting a higher proportion of the live loading compared with the east main girder. This may be due to additional vertical loads induced from the track curvature which creates slightly unbalanced loading on the west track. Another potential explanation for this difference may stem from the dominant rail traffic patterns on the bridge in which more heavily-loaded (e.g. Class 221 versus Class 350 train types) passenger trains tend to travel on the west line (in this case southbound). This would have the effect of skewing the moment demand envelopes. Therefore, future research will include collecting and processing data from a larger number of trains. Daily, weekly, monthly and seasonal effects will also be considered when revising and interpreting the percentage utilisation estimates.

\section{FUTURE TOOLS FOR LONG-TERM MONITORING OF SELF-SENSING BRIDGES}

This monitoring project has highlighted the variety of information that can be captured for assessing bridges when they are constructed with an integrated sensing system. It has also revealed that if self-sensing structures are to be widely adopted across all levels of infrastructure then consideration of the long term management, analysis and interpretation of the information generated is critical. The following sections introduce two new areas of research currently being explored for increasing the value of monitoring data.

\subsection{Sensing-integrated BIM models}

Building information models (BIM), are digital representations of physical assets which are typically employed during the design and construction phases. However, there is growing interest to leverage BIM in facilities and asset management (Burcerik-Gerber 2012). Preliminary work has been completed in developing BIM elements for sensors which can store continuous strain and temperature data from FBGs, BOTDR or other sensor types and provide a visualization directly within the BIM model (Delgado et al. 2017). This proposed approach will enable engineers and asset managers to use a common interface in which they can use the information generated during an asset's operation. In terms of long-term inspections, this approach can help to avoid subjectivity, increase reliability, and provide an integrated long-term data management system. 


\subsection{Data-centric engineering}

Through a collaboration between the Lloyds Register Foundation funded program on Data Centric Engineering (DCE) at the Alan Turing Institute and the Cambridge Centre for Smart Infrastructure and Construction (CSIC) at the University of Cambridge, a multi-disciplinary team of engineers and data scientists are working to characterize and analyse the vast quantities of dynamic strain data gathered from the selfsensing bridges and other structures.

DCE may be viewed as an approach for learning about engineering structures which leverages physicsbased (e.g. finite element) models which are updated based on sensor data and statistical (data-driven) models that incorporate prior knowledge of the physical asset. This combined model would provide the self-sensing structure with a 'digital twin' which would exist alongside the asset and be updated and refined throughout its service life (Lau et al. 2018a).

This collaboration has thus far developed streaming statistical models and temporal de-trending techniques which have been successfully applied to large, continuously recorded strain data sets collected from Intersection Bridge 5 (Lau et al. 2018b).

It is envisioned that merging concepts such as sensing-integrated BIM models and 'digital twins' will provide powerful future platforms on which to build additional value into the data generated from condition monitoring systems.

\section{CONCLUSIONS}

This paper has discussed the creation of two fibreoptic based self-sensing railway bridge prototypes. The bridges included Underbridge 11, an 11.2 metre prestressed concrete girder bridge with a cast in-situ concrete deck, and Intersection Bridge 5, a 26.8 metre steel half-through skewed I-girder bridge with a composite concrete deck. Discussions of the sensor technologies employed along with the installation techniques and sensor topologies are presented. Based on two years of collected monitoring data, the primary findings of this study include:

1. Pertaining to the prestressed concrete girder Underbridge 11, a comparison of the measured prestress losses in the internal (TY7) beams and the external (TYE7) edge beams indicated a higher prestress loss for the TYE7 beams in their first 2 years in-service. Based on the change in prestress, the TY7 and TYE7 beams had reached $77 \%$ and $62 \%$, respectively of the Eurocode 2 predicted long-term losses.

2. Two methods for estimating the midspan deflection of the Intersection Bridge 5 east main girder under live loading were investigated as part of this study. The first method involved applying an algorithm which considered Euler-Bernoulli beam theory and moment-curvature relationships to calculate vertical deflection using FBG-measured horizontal strains. In addition, a videogrammetry system was also deployed to measure deflections of the east main girder. It was found that both methods produced similar time-deflection profiles however, the videogrammetry deflections were on average $18 \%$ greater than those estimated from the FBG strain measurements. While additional monitoring data is required, these initial results were found to be promising.

3. Based on the monitoring data collected from 12 passenger trains passing over Intersection Bridge 5, moment demand envelopes for both main girders were derived in order to compare with the design live load moment capacity. Based on their moment envelopes, the west and east main girders' structural utilization percentages under live load were $9.4 \%$ and $7.1 \%$, respectively. It was noted however, that further monitoring is planned to develop a larger moment demand envelope data set that will also consider the effect of environmental factors such as temperature on the measure moment demand.

This paper concludes with a discussion of current advances in BIM models which are capable of storing, managing and visualizing data obtained from sensor systems. A new area of research referred to as data-centric engineering is introduced where research efforts are currently underway to integrate finite element models with advanced statistical models for data generated from self-sensing bridges.

\section{ACKNOWLEDGEMENTS}

The authors would like to acknowledge EPSRC, Innovate UK and the Lloyd's Register Foundation for funding this research through the Centre for Smart Infrastructure and Construction (CSIC) Innovation and Knowledge Centre and the Alan Turing Institute. Research related to installation of the sensor system was carried out under EPSRC grant no. $\mathrm{EP} / \mathrm{L} 010917 / 1$. Data related to this publication is available at the University of Cambridge data repository.

\section{REFERENCES}

Becerik-Gerber B., Jazizadeh F., Li N., and Calis G. 2012. Application Areas and Data Requirements for BIMEnabled Facilities Management. J. Constr. Eng. Manag., American Society of Civil Engineers, 138(3), 431-442.

BSI. 2004. EN 1992-1-1:2004 Eurocode 2: Design of concrete structures. Part 1-1: General rules and rules for buildings. British standards institution, Chiswick, U.K.

BSI. 2005. BS EN 1994-2:2005 Eurocode 4: Design of composite steel and concrete structures. Part 2: General 
rules and rules for bridges. British standards institution, Chiswick, U.K.

BSI. 2006. BS EN 1993-2:2006 Eurocode 3: Design of steel structures. Part 2: steel bridges. British standards institution, Chiswick, U.K.

Butler L.J., Gibbons N., He P., Middleton C.R. and Elshafie M.Z.E.B. 2016. Evaluating the early-age behaviour of fullscale prestressed concrete beams using distributed and discrete fibre optic sensors. Construction and Building Materials, 126: 894 - 912.

Cardini A.J. and DeWolf J.T. 2009. Long-term structural health monitoring of multi-girder steel composite bridge using strain data. Journal of Structural Health Monitoring, 8(1): $47-58$.

Centre for Smart Infrastructure and Construction (CSIC). 2016. Smart infrastructure: getting more from strategic assets. White paper: 7 pgs.

Chan T.H.T., Yu L., Tam H.Y., Ni Y.Q., Liu S.Y. 2006. Chung W.H., and Cheng L.K. Fiber Bragg Grating Sensors for Structural Health Monitoring of Tsing Ma Bridge: Background and Experimental Observation. Engineering structures, 28:648 - 659.

Costa B.J.A. and Figuieras J.A. 2012. Evaluation of a strain monitoring system for existing steel railway bridges. Journal of Constructional Steel Research, 72: 179 - 191.

Delgado J.M.D., Butler L.J., Brilakis I., Elshafie M.Z.E.B. and Middleton C.R. 2017. Structural performance monitoring using data-driven and dynamic BIM environments. ASCE Journal of Computing in Civil Engineering. In press.

Glišić, B., and Inaudi, D. 2008. Fibre optic methods for structural health monitoring. John Wiley \& Sons. 262 pgs.

Gowripalan N., Li J. \& Wang J.J. 2016. Monitoring of bridges using fibre optic sensors (FOS) and digital image correlation (DIC) techniques - an Australian perspective, Concrete in Australia 42(2): 55 - 59.

Institution of Civil Engineers (ICE). 2017. Intelligent assets for tomorrow's infrastructure: guiding principles. ICE guidance paper. London U.K., 28 pgs.

Jemli M.E., Karoumi R., and Lanaro R. 2003 Monitoring of the New Årsta Railway Bridge Using Traditional and Fibre Optic Sensors. Smart Structures and Materials, 5057: 279 288.

Kreuzer M. 2006. Strain measurement with fiber Bragg grating sensors. HBM, Darmstadt, S2338.

Lau F-D.H., Butler L.J., Adams N.M., Elshafie M.Z.E.B., and Girolami M.A. (2018a). The role of statistics in data-centric engineering. Statistics and Probability Letters, Special Issue on the Role of Statistics in the Era of Big Data. Article in press.

Lau F-D.H., Adams N.M., Girolami M.A., Butler L.J. and Elshafie M.Z.E.B. (2018b). Real-time statistical modelling of data generated from self-sensing bridges. Journal of Smart Infrastructure and Construction, Proceedings of the Institution of Civil Engineering, Themed Issue on Big Data Analysis. Article in press.

Lydon M., Robinson D., Taylor S.E., Amato G., O'Brien E.J. \& Uddin N. 2017. Improved axle detection for bridge weigh-in motion systems using fiber optic sensors. Journal of Civil Structural Health Monitoring, 7: 325 - 332.
Measures R.M., LeBlanc M., Liu K., Ferguson S., Valis T., Hogg D., Turner R. \& McEwen. 1992. Fiber optic sensors for smart structures. Optics and Lasers in Engineering 16: $127-152$.

Middleton C.R., Fidler P.R.A., and Vardanega P.J. (2016). Bridge monitoring: a practical guide, Thomas Telford Limited, ICE Publishing, 120 pages.

Regier R. and Hoult N.A. 2014. Distributed strain behaviour of a reinforced concrete bridge: case study. ASCE Journal of Bridge Engineering, 19(12): 1 - 9.

Scott R.H., Banerji P., Chikermane S., Srinivasan S., Basheer P.A.M., Surre F., Sun T. \& Grattan K.T.V. 2013. Commissioning and evaluation of a fiber-optic sensor system for bridge monitoring. IEEE Sensors Journal, 13(7): 25552562 .

Tennyson R.C., Mufti A.A., Rizkalla S., Tadros G. \& Bemokrane B. 2001. Structural health monitoring of nnovative bridges in Canada. Smart Materials and Structures, 10: $560-573$.

Todd M.D., Johnson G.A., Chang C.C. 2000. Real-time girder deflection reconstruction using a fibre Bragg grating system. Proc. IMAC XVIII: a Conf. on Structural Dynamics, 1313 1319.

Vardanega P.J., Webb G.T., Fidler P.R.A. \& Middleton C.R. 2016. Assessing the potential value of bridge monitoring systems. Bridge Engineering, Proceedings of the Institution of Civil Engineers, 169(BE2):126 - 138.

Vurpillot S., Inaudi D., Scano A. 1996. Mathematical model for the determination of vertical displacement from internal horizontal measurements of a bridge. Smart systems for bridges, structures, and highways. SPIE Smart Structures and Materials, 2719:46 - 53.

Webb G.T., Vardanega P.J. \& Middleton C.R. 2015. Categories of SHM deployments: technologies and capabilities. ASCE Journal of Bridge Engineering, 20(11): 1 - 12.

Webb G.T., Vardanega P.J., Hoult N.A., Fidler P.R.A., Bennet P.J. \& Middleton C.R. 2017. Analysis of fibre-optic strainmonitoring data from a prestressed concrete bridge. ASCE Journal of Bridge Engineering, 22(5): 1 - 14. 